\title{
Phagocytosis of Spermatozoa and Latex Beads by Epithelial Cells of the Ampulla Vasis Deferentis of the Rabbit: A Combined SEM and TEM Study*
}

\author{
Masahiro Murakami, Tomihide Nishida, Mitsuru Shiromoto \\ and Tetsuo INOKUCHI \\ Department of Anatomy (Prof. M. Murakami), Kurume University School of Medicine, Kurume, Japan \\ Received February 28, 1985
}

\begin{abstract}
Summary. The fine structure in the ampullary region of the vas deferens of the rabbit was observed by scanning and transmission electron microscopy, with emphasis on the occurrence of epithelial spermiophagy. The epithelial cells were cuboidal or low columnar and contained moderately developed organelles. These cells, like luminal macrophages, were found to be not only involved in spermiophagy but also capable of actively taking up latex beads administrated intraluminally. Taking into consideration the previous findings in some other species, the epithelial spermiophagy seems to be a common event in the vas deferens of mammals.
\end{abstract}

Extensive spermiophagy by the epithelial cells in the terminal region of the vas deferens was first reported by CoOPER and HAMilton (1977) in the rat. Later the same phenomenon has been documented in the terminal or ampullary region of the vas deferens of certain mammals including the cat (Murakami et al., 1984a), monkey (RAMOs, 1979; Murakami et al., 1981) and also man (Riva et al., 1982; Murakami et al., 1982). In the cat, our observations (Murakami et al., 1984b) confirmed that the epithelial cells in this location reveal phagocytosis of not only spermatozoa but also inert particles as latex beads injected to the lumen. However, it has not yet been determined whether epithelial phagocytosis in the terminal vas deferens is a common event in mammalian species or whether there is species variation in such a cell activity. The epithelium of the ampulla vasis deferentis of the rabbit as studied either by transmission (TEM) or scanning electron microscopy (SEM) or both (NICANDER and Schantz, 1961; KunkeLMANN and KÜHNEL, 1984) has not revealed any morphological evidence to support the existence of spermiophagy.

In the present study on the fine structure of the ampulla vasis deferentis of the rabbit with SEM and TEM, special attention was paid to elucidate whether or not the epithelial cells can take in spermatozoa and luminally injected latex beads in a phagocytic manner.

*This investigation was supported in part by a grant from the Ishibashi-Foundation. 


\section{MATERIALS AND METHODS}

Four adult rabbits weighing approximately $3 \mathrm{~kg}$ were used in this study. In two rabbits anesthetized with peritoneally applied Nembutal, $0.5 \mathrm{ml}$ of physiological saline solution containing polyvinyl toluene latex beads $(0.3 \mu \mathrm{m}$ and $1.0 \mu \mathrm{m}$ in diameter) was injected into the lumen of both scrotal vasa deferentia for $30 \mathrm{~min}$ prior to sacrifice. The remaining two animals did not receive such treatment. Then all the animals, under Nembutal anesthesia, were perfused through the ascending aorta with $2.5 \%$ paraformaldehyde and $2 \%$ glutaraldehyde in cacodylate buffer ( $\mathrm{pH} 7.2)$. After perfusion, the whole length of the vas deferens from its proximal to ampullary region was taken out and placed in the same fixative for additional $2 \mathrm{hrs}$. The tissue was washed in cacodylate buffer and postfixed in $2 \% \mathrm{OsO}_{4}$ buffered with phosphate $(\mathrm{pH} 7.2)$. For TEM study, specimens were dehydrated through a graded ethanol series and embedded in epoxy resin. Thin sections were cut with a diamond knife on a Reichert-Yung microtome, stained with uranyl acetate and lead citrate, and examined with a HitachiH 500 TEM. The specimens for SEM were similarly dehydrated through a graded ethanol series, critical point-dried in liquid carbon dioxide, briefly coated with platinum in an ion sputter coater and examined with a Hitachi-HFS2 field-emission SEM. Organic reagents such as acetone, propylene oxide and isoamyl acetate were not used in the present study because they tended to dissolve the latex beads.

\section{RESULTS AND DISCUSSION}

The ampulla vasis deferentis of the rabbits dilates as a spindle-shaped enlargement; its cavity consists of one large lumen located centrally and some irregular diverticula arranged radially around it (Fig. 1). Individual diverticula communicate with each other at one end and with the central lumen through a narrow opening at the other. The epithelium lining both the central lumen and the diverticula is composed of low columnar or cuboidal epithelial cells among which a few flattened basal cells are interspaced. The epithelial cells contain moderate numbers of mitochondria, a poorlydeveloped Golgi complex, many ribosomes, sparse tubules of rough endoplasmic reticulum, abundant microfilaments, a few dense bodies with heterogenous inclusion and infrequent lipid droplets. The large and spherical nuclei with clumps of condensed chromatin occupy the center of the cytoplasm. Granules suggesting a secretory activity cannot be encountered either in the Golgi area or in other regions of the cytoplasm (Fig. 2). The topography and histology of the epithelium of the ampulla vasis deferentis in the rabbit, as just described, are essentially similar to that reported by previous authors (Nicander and Schantz, 1961; Kunkelmann and Kühnel, 1984).

An SEM view of the apical surface of the epithelial cells is either a flat or slightly bulging hexagonal outline and in the fashion of cobble stone pavement. A few spermatozoa can be seen attaching themselves to the luminal surface of both the central lumen and diverticula (Fig. 3).

Fig. 1. Longitudinal section of the ampulla vasis deferentis showing its luminal configuration. The cavity consists of a central lumen $(C L)$ and diverticula interconnecting each other and opening together onto the central lumen. $\times 30$

Fig. 2. General view of the epithelium of the ampulla in a thin section. The epithelium is composed of cuboidal or low columnar cells with moderately developed organelles and a few basal cells with scanty cytoplasm. $\quad \times 5,100$ 


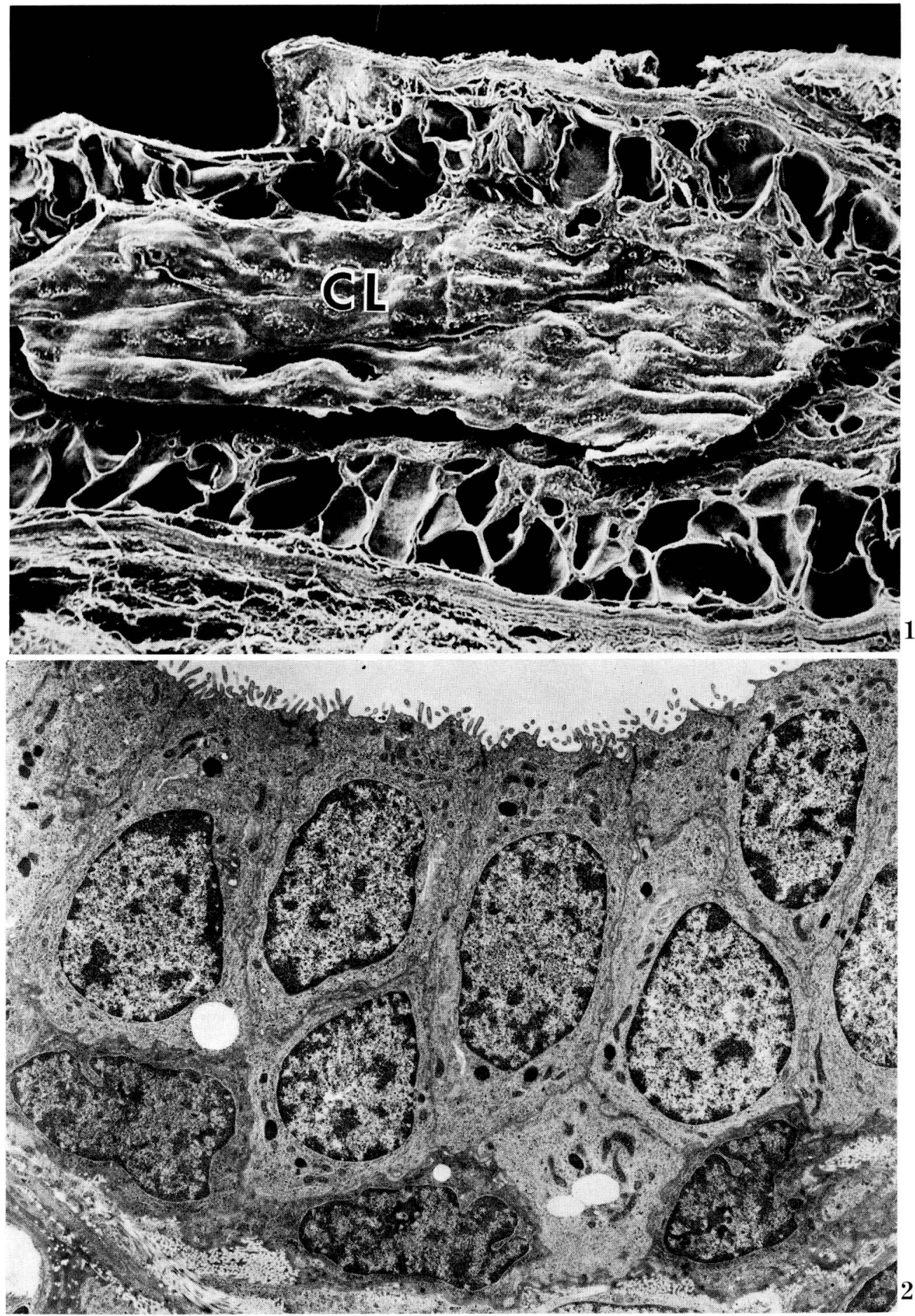

Fig. 1 and 2. Legends on the opposite page. 


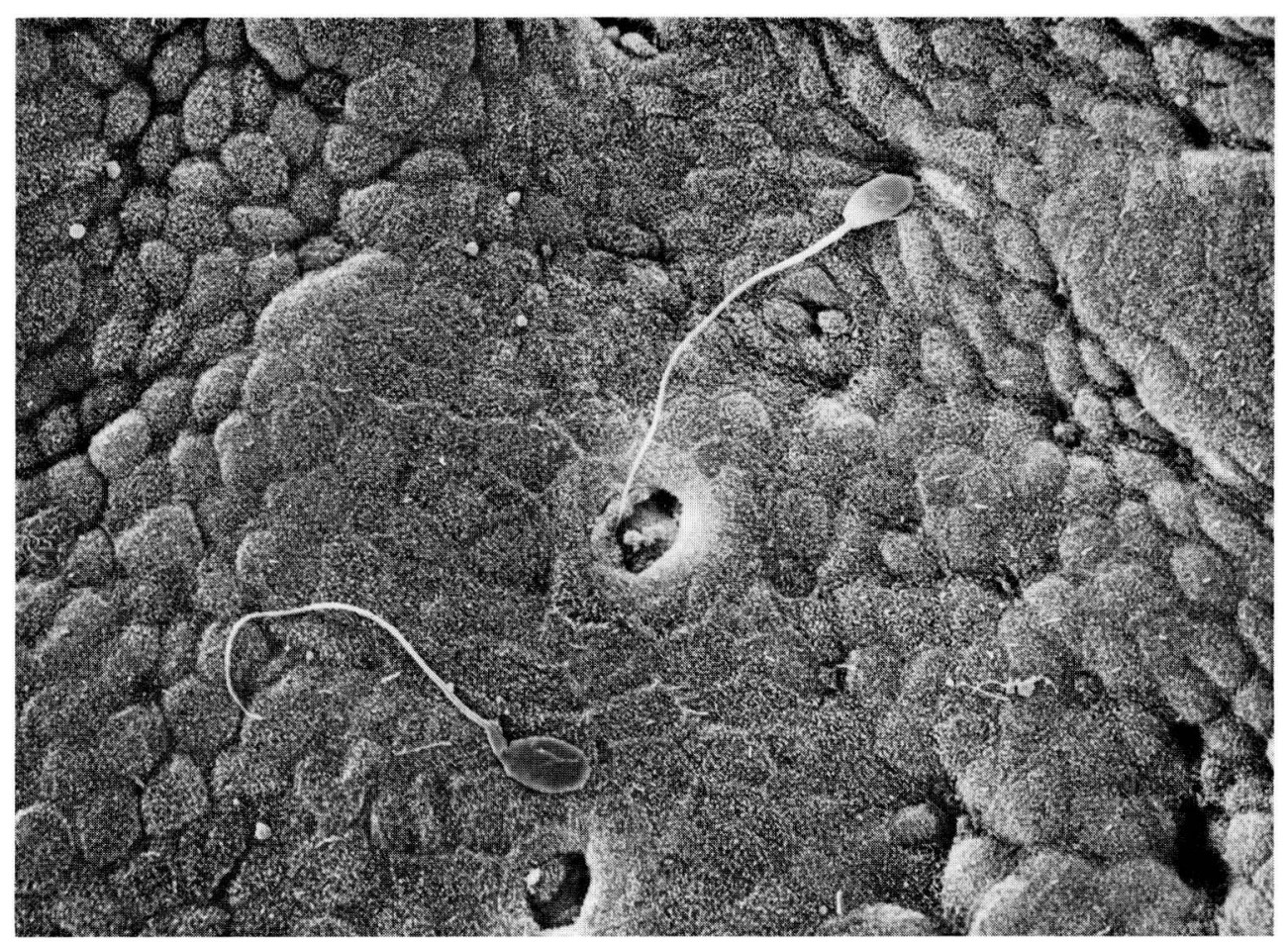

Fig. 3. Overview of the luminal surface of the central lumen. The luminal surface of the epithelial cells is flat or slightly protruded and covered by stubby microvilli. Round or slit-like apertures are openings to the diverticula. A few spermatozoa are also visible on the luminal surface. $\times 1,200$

A noteworthy observation was the spermiophagy found by SEM in the ampullary epithelial cells in the rabbit. Its incidence is infrequent in the rabbit although quite frequent in the cat and monkey as reported previously (Murakami et al., 1981, 1984a). Spermatozoa are trapped by pseudopod-like flaps arising from the apical surface of the epithelial cells as shown in Figures 4 and 5 . In the rabbit the phagocytosis of spermatozoa begins primarily at their head, while it may start not only at the head but also at the tail of spermatozoa in the monkey and man (Murakami et al., 1981; Riva et al., 1981), and even at the middle area in the cat (Murakami et al., 1984a).

In thin sections, spermatozoa at various stages of disintegration following phagocytosis were observed within phagocytic vacuoles in the cytoplasm of the epithelial cells (Fig. 6). The fate of these ingested spermatozoa is essentially the same as that described in the epithelium of the same region of the vas deferens of the cat (Murakami et al., 1984a) and the rat (Cooper and Hamilton, 1977). Sporadic spermiophagy by epithelial cells has already been reported in other parts of the male reproductive system such as the seminiferous tubules (Dym, 1974; NyKänen, 1979), rete testis (Burgos and

Fig. 4. Micrograph showing a spermatozoon being engulfed by an epithelial cell. Its middle piece is enveloped next to the head by a sleeve-like pseudopod extended from an epithelial cell. $\times 3,800$. Insert: Higher magnification of a part of the spermatozoon illustrated in Figure 4 . $\times 16,800$

Fig. 5. An additional example of epithelial spermiophagy similar to that shown in Figure 4. $\times 4,200$. Insert: Higher magnification of a captured spermatozoon seen in Figure $5 . \quad \times 5,700$ 


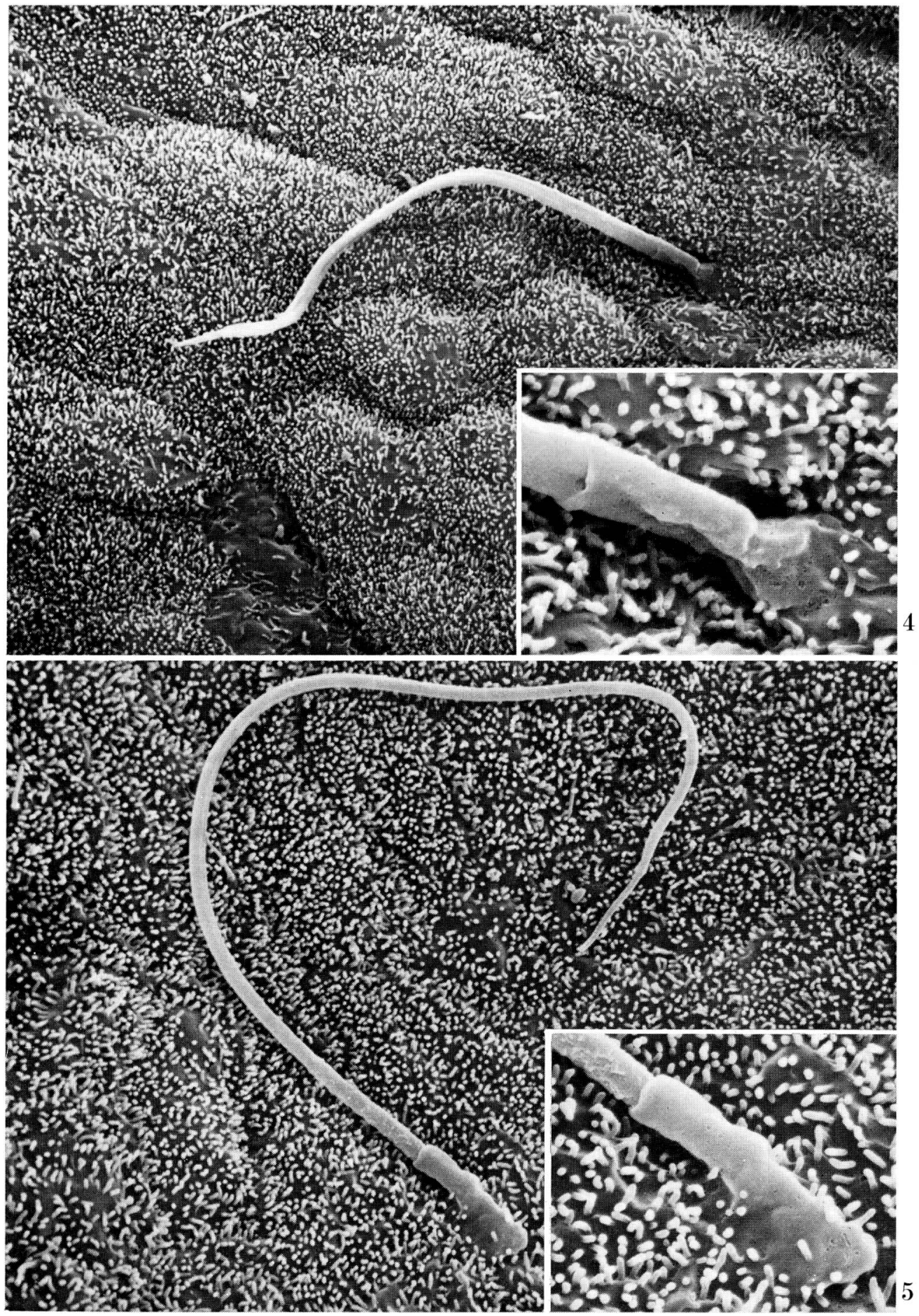

Fig. 4 and 5. Legends on the opposite page. 


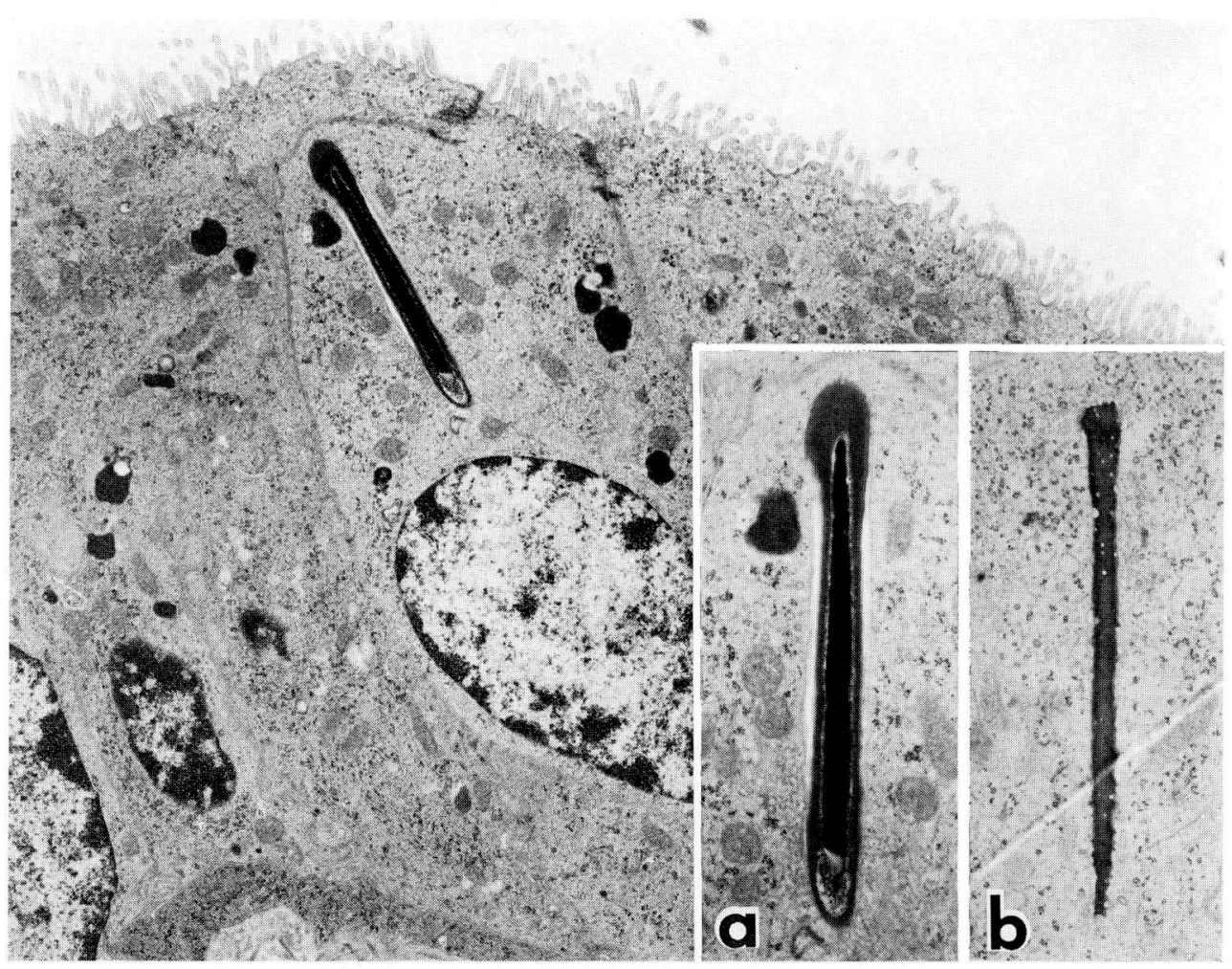

Fig. 6. Thin section through the epithelium of the ampulla vasis deferentis indicating a phagocytosed spermatozoon in the cytoplasm. $\times 7,000$. Insert a: Higher magnification of the spermatozoon shown in Figure 6. This spermatozoon seems in an initial stage of ingestion because its cell membrane and acrosome remain intact. $\times 1,200$. Insert b: A phagocytosed spermatozoon in the cytoplasm of an epithelial cell. This spermatozoon may be in a more advanced stage of degeneration because its head has become more condensed and lacks the cell membrane and the acrosome. $\times 7,000$

Cavicchia, 1975; Holstein, 1978; Goyal, 1982), efferent ductules (Goyal, 1982), ejaculatory duct (Cossu et al., 1983) and seminal vesicles (Riva et al., 1981) in some mammals including man.

In the lumen of the ampulla vasis deferentis, macrophages are often seen attached to the apical surface of the epithelial cells, and many of them are loaded with a cluster of spermatozoa (Fig. 7). Spermiophagy by luminal macrophage has recently been documented as occurring normally along the entire length of the male reproductive tract including the vas deferens in some mammals (CoOper and Hamilton, 1977; Kennedy and Heidger, 1979; Holstein, 1978; Murakami et al., 1978, 1984a; Goyal, 1982).

SEM micrographs of the animals with latex beads injected into the vas deferens

Fig. 7. Micrograph showing a luminal macrophage in the ampulla vasis deferentis. Note that the macrophage is located with a cluster of spermatozoa with or without a cytoplasmic droplet. $\times 3,000$

Fig. 8. Luminal surface of the ampulla vasis deferentis of the rabbit to which latex beads were injected. A number of latex beads are located on or among microvilli of the epithelial cells. $\times 27,000$. Insert: Higher magnification of a part of Figure 8. A latex bead is just trapped by a tongue-like pseudopod extending from an epithelial cell. $\times 39,400$ 


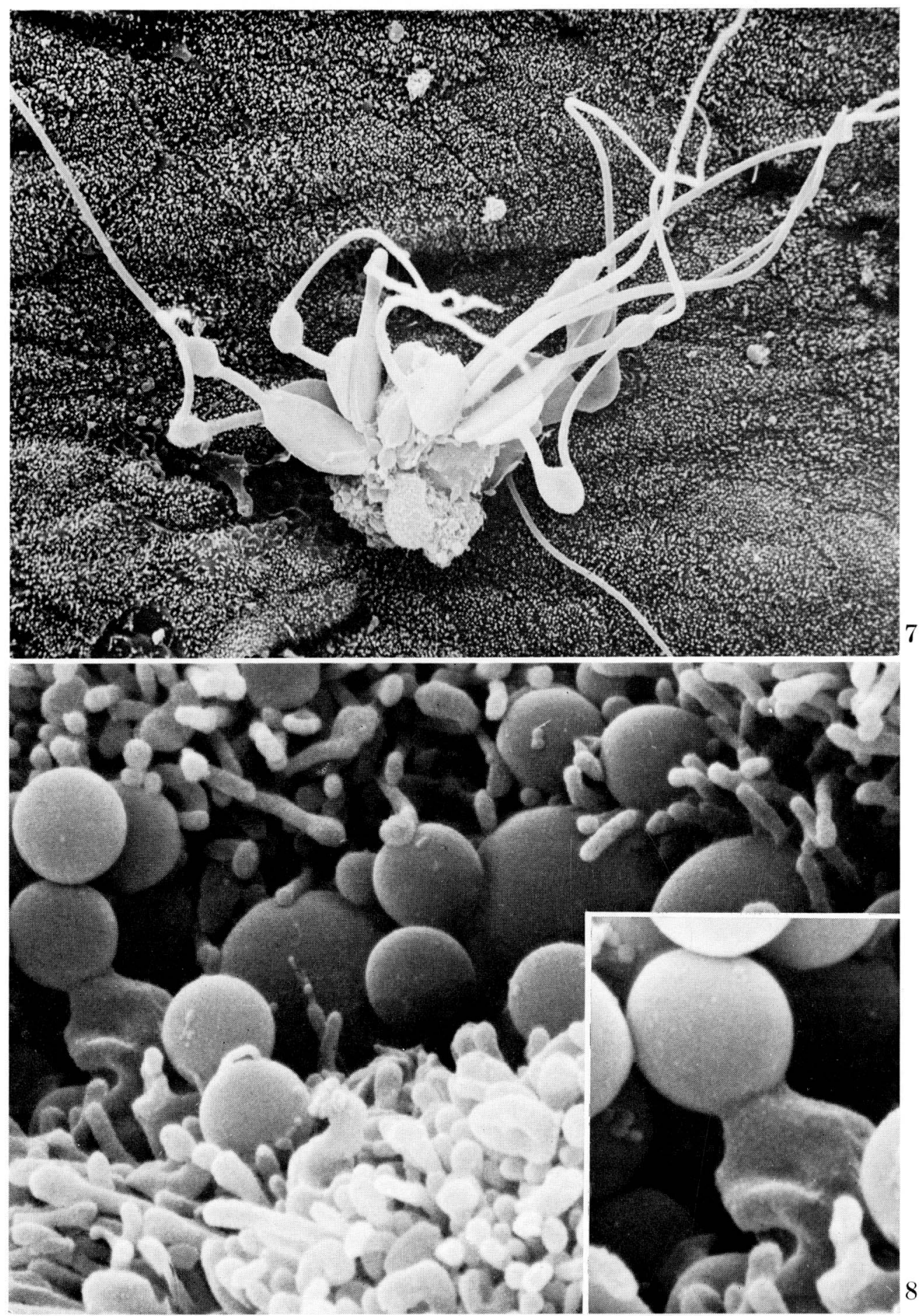

Fig. 7 and 8. Legends on the opposite page. 


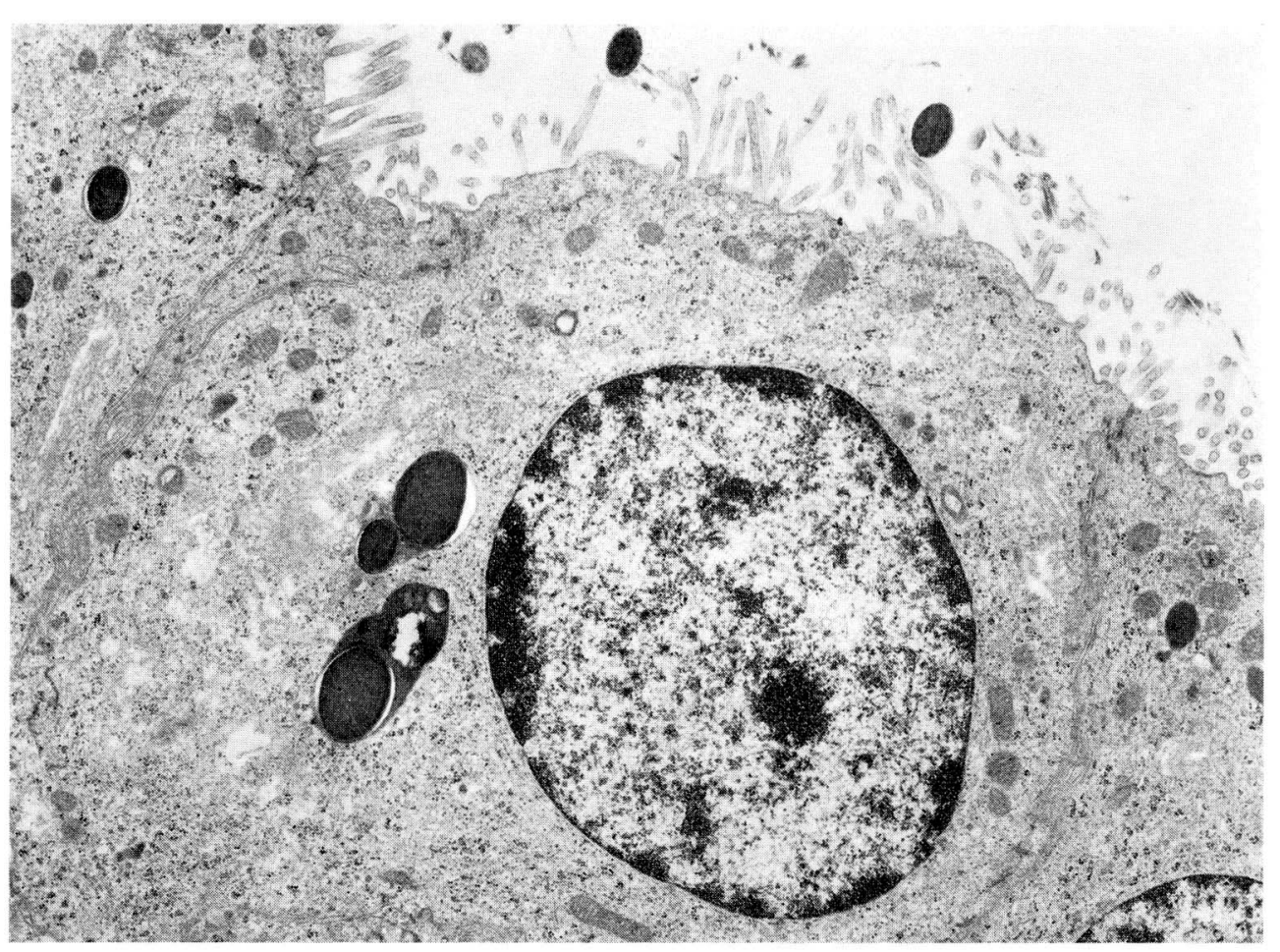

Fig. 9. A thin section through the epithelial cells of the ampulla vasis deferentis. Latex beads are contained alone or in groups within phagocytic vacuoles or dense bodies in the cytoplasm. $\times 9,900$

demonstrate numerous beads located on and among the microvilli of the epithelial cells. Some of the beads are observed to be captured singly or in groups by cytoplasmic pseudopods extended from the epithelial cells (Fig. 8) as has been seen in the cat (Murakami et al., 1984b).

In TEM, engulfed latex beads were confirmed to be either enclosed in phagocytic vacuoles or embedded within lysosomal dense bodies in the cytoplasm of the epithelial cells (Fig. 9). Besides the epithelial cells, luminal macrophages were also actively taking up the latex beads injected, though this is not illustrated here.

The results presented in this study clearly indicate that the epithelial cells of the ampulla vasis deferentis of the rabbit are capable of ingesting spermatozoa and even latex beads at variance with the finding of the previous authors (NICANDER and SCHANTZ, 1961; Kunkelmann and KüHnel, 1984), who failed to detect spermiophagy by the epithelial cells in the ampullary region of rabbit vas deferens. This phenomenon occurring in the vas deferens is probably common in mammalian species, because our unpublished observation indicate that the dog vas deferens also is capable of taking up spermatozoa and latex beads in the fashion of epithelial phagocytosis. The functional significance of the epithelial phagocytosis is unknown, but it is conceivable that the epithelial cells act to dispose damaged or excess spermatozoa passing through the lumen. The same cells also take up latex beads which are foreign in nature. 


\section{REFERENCES}

Burgos, M. H. and J. C. Cavicchia: Phagocytic activity in the epithelium of the rete testis. In: Proc. 10th. Int. Congr. Anat. Tokyo, Science Council of Japan, 1975 (p. 444).

Cooper, T. G. and D. W. Hamilton: Phagocytosis of spermatozoa in the terminal region and gland of the vas deferens of the rat. Amer. J. Anat. 150: 247-268 (1977).

Cossu, M., M. F. Marcello, E. Usai, F. Testa Riva and A. Riva: Fine structure of the epithelium of the human ejaculatory duct. Acta anat. 116: 225-233 (1983).

Dym, M.: The fine structure of monkey Sertoli cells in the transitional zone at the junction of the seminiferous tubules with the tubuli recti. Amer. J. Anat. 140: 1-26 (1974).

Goyal, H. O.: Light microscopic and ultrastructural evidence of epithelial phagocytosis of sperm in the rete testis and ductuli efferentes in the bull. Amer. J. Vet. Res. 43: 785-790 (1982).

Holstein, A. F.: Spermatophagy in the seminiferous tubules and excurrent ductus of the testis in rhesus monkey and in man. Andrologia 10: 331-352 (1978).

Kennedy, S. W. and P. M. Heidger, Jr.: Fine structural studies of the rat vas deferens. Anat. Rec. 194: 159-180 (1979).

Kunkelmann, H. and W. Kühnel : Zur Morphologie der Ampulla ductus deferentis von Kaninchen. Transmissions- und rasterelektronenmikroskopische Untersuchungen. Acta anat. 118: 1-12 (1984).

Murakami, M., A. Sugita, T. Shimada and T. Yoshimura: Scanning electron microscope observation of the seminal vesicle in the Japanese monkey with special reference to intraluminal spermiophagy by macrophages. Arch. histol. jap. 41: 275-283 (1978).

Murakami, M., A. Sugita, T. Shimada, M. Hamasaki, T. Morizono and K. Nakamura: SEM observation of the male reproductive system in the Japanese monkey. In: (ed. by) K. Tanaka and T. Fujita: Scanning electron microscopy in cell biology and medicine. Excerpta Medica, Amsterdam-Oxford-Princeton, 1981 (p. 355-359).

Murakami, M., A. Sugita and M. Hamasaki: The vas deferens in man and monkey: spermiophagy in its ampulla. In: (ed. by) E. S. E. Hafez and P. Kenemans: Atlas of human reproduction by scanning electron microscopy. MTP Press Ltd., Lancaster-Boston-Hague, 1982 (p. 187-195).

Murakami, M., T. Nishida, S. Iwanaga and M. Shiromoto: Scanning and transmission electron microscopic evidence of epithelial phagocytosis of spermatozoa in the terminal region of the vas deferens of the cat. Experientia 40: 958-960 (1984a).

Murakami, M., S. Iwanaga, T. Nishida and T. Aiba: Phagocytosis of latex beads by the epithelial cells in the terminal region of the vas deferens of the cat: SEM and TEM study. Andrologia 16: 548-553 (1984b).

Nicander, L. and B. Schantz: On the ultrastructure of the glandular epithelium of the ampulla ductus deferentis in rabbits. Acta morphol. neerl. scand. 4: 172-179 (1961).

Nykänen, M.: Fine structure of the transitional zone of the rat seminiferous tubule. Cell Tiss. Res. 198: 441-454 (1979).

Ramos, A. S.: Morphologic variations along the length of the monkey vas deferens. Arch. Androl. 3: 187-196 (1979).

Riva, A., M. Cossu, E. Usai and F. Testa-Riva: Spermiophagy by epithelial cells of the seminal vesicle and of the ampulla ductus deferentis in man: A scanning and transmission EM study. In: (ed. by) G. Frajese, E. S. E. Hafez, C. Conti and A. Fabbrini: Oligozoospermia: Recent progress in andrology. Raven Press, New York, 1981 (p. 45-53).

Riva, A., F. Testa-Riva, E. Usai and M. Cossu: The ampulla ductus deferentis in man, as viewed by SEM and TEM. Arch. Androl. 8: 157-164 (1982).

村上正浩

T 830 久留米市旭町 67

久留米大学医学部

解剖学教室
Prof. Dr. Masahiro Murakami

Department of Anatomy

Kurume University School of Medicine

Asahi-Machi 67

Kurume, 830 Japan 